\title{
VISTIENDO LA IDENTIDAD YUCATECA. ETNOMERCANCÍA, TRADICIÓN Y MODERNIDAD
}

\section{WEARING YUCATECAN IDENTITY. ETHNO-COMMODITY, TRADITION AND MODERNITY}

\section{Francisco Fernández Repetto* Alma Teresa Medina Várguez ${ }^{\star *}$}

\begin{abstract}
Resumen: En este artículo enfatizamos, en la primera parte, cómo el vestido regional constituye uno de los pilares de la identidad yucateca, una identidad menor, construida en contraste y oposición a una identidad mayor: la mexicana. En un segundo apartado, discutimos las ventajas y límites de los términos artesanía y etnomercancía para caracterizar mejor al traje regional yucateco. Finalmente, proponemos que los diferentes papeles tomados por las versiones masculina y femenina del traje regional constituyen, respectivamente, referencias directas a la modernidad y la tradición.
\end{abstract}

Palabras clave: traje regional yucateco, identidad menor, artesanía, etnomercancía.

\footnotetext{
* Universidad Autónoma de Yucatán. Líneas de investigación o temáticas de interés: antropología visual, antropología del turismo, representaciones socioculturales, antropología de la educación superior. Dirección electrónica: frepetto@correo.uady.mx. Dirección postal: km 1 Carr. Mérida-Tizimín. Cholul, Mérida, Yucatán. CO 97305. ORCiD: https://orcid.org/00000003-4759-1410.

** Universidad Autónoma de Yucatán. Líneas de investigación o temáticas de interés: consumo cultural, artesanías, representaciones socioculturales. Dirección electrónica: almateresa. medina@gmail.com. Dirección postal: km 1 Carr. Mérida-Tizimín. Cholul, Mérida, Yucatán. CO 97305 .
}

Fecha de recepción: 17/02/2019, fecha de aceptación: 07/05/2019, fecha de publicación: $31 / 01 / 2020$.

(cc) EY-NC-ND Páginas 241-275 
Abstract: In this article, first we stress how the regional dress constitutes one of the pillars of the Yucatecan identity, a minor identity, built upon the contrast and opposition to a major identity, the mexican one. In the second part we discuss the advantages and limitations of the terms handcraft and ethno-commodity to better characterize the Yucatecan regional dress. Finally, we propose that the different roles taken by the male and female versions of the regional dress constitute a direct reference respectively, to modernity and tradition.

Keywords: Yucatecan regional dress, minor identity, handcraft, ethnocommodity.

\section{Introducción}

El estudio sobre los trajes regionales es vasto y se ha abordado desde distintas aristas, entre las que destacan aspectos tales como su manufactura, incluyendo sus materiales, técnicas, tecnologías y procesos (Hendrickson 1995 y 1997; Greenfield, S/F). Desde una perspectiva de género se destaca la participación de la mujer en el proceso de producción y en los de socialización y endoculturación de las niñas (Greenfield, $S / F$ ); proceso que es también un importante factor en la construcción y expresión de la identidad de los grupos socioculturales y étnicos (Saltzman, 2007; Valenciano-Mañé 2012; Otzoy, 1992; Hendrickson, 1997).

La estrecha relación entre los trajes regionales y su empleo como imagen y símbolo de la identidad a distintos niveles (local, regional, nacional, global), convierte a este traje en uno más de los distintos territorios de confrontación y disputa entre quienes portan el traje de manera cotidiana y quienes lo usan para fines distintos, especialmente para la construcción de la identidad nacional y para el turismo (Otzoy, 1992; Valenciano-Mañé, 2012; Hendickson, 1997; Walton, 2019).

Las distintas maneras en las que se denomina a este tipo de trajes reflejan su dinámica en contextos variados. Así, por ejemplo, cuando se les llama trajes típicos tienden a asociarse con el mercado turístico y con la autenticidad del producto; en contraste, cuando se habla de trajes tradicionales se construye una idea sobre la base del tiempo y la distancia, como algo que sobrevive y 
refleja valores y costumbres de la localidad o de la región. Cuando se les trata como trajes regionales suponemos dos niveles, que refieren ya sea a la nación o a ciertas partes de la nación, en consonancia con el contexto en el que se presenta. Será nacional en un contexto global, pero regional en un contexto nacional. Otra manera de llamarles sería apelando directamente al grupo étnico que lo porta, en este sentido incluiríamos el nombre del grupo étnico para denominarlo, de esta manera emplearíamos los términos traje regional yucateco, o traje maya, para referirnos a la indumentaria que caracteriza un territorio.

Para Yucatán, el traje regional yucateco se expresa y sintetiza en el terno ${ }^{1}$, éste se ha empleado desde finales del siglo XIX (Millet y Quintal, 1994) como un mecanismo de integración del estado, y con ello de la especificación y diferenciación del mismo en relación con la nación mexicana. Se ha utilizado, junto con otros aspectos tales como el lenguaje (español yucateco) (Güémez, 2011), la celebración del día de muertos (Janal Pixán) (Fernández Repetto y Negroe Sierra, 2008), las fiestas patronales (Fernández Repetto y Negroe Sierra, 2010; Quintal Avilés y otros, 2003), la comida (Ayora 2012) y la música (Vargas-Cetina, 2017), como una manera de particularizar la historia, hacerla única y celebrar las diferencias con la nación, construyendo lo que podríamos denominar una identidad menor (la identidad yucateca) en el marco de una identidad mayor (la identidad nacional-mexicana), que la subsume y con la cual se enfrenta.

Mérida, la capital del estado de Yucatán, fue el sitio en el que cuajó la creación del traje regional yucateco. Tomado de las piezas de vestido que las "mestizas" empleaban en las vaquerías para bailar jarana ${ }^{3}$, se trasladó,

\footnotetext{
${ }^{1}$ Güémez Pineda define al terno como " $[t]$ raje regional, o ceremonial yucateco. Por antonomasia se aplica al conjunto de tres prendas: hipil, jubón y fustán, que constituyen el vestido de gala de la mestiza yucateca. El hipil, por lo general de tela blanca, lleva en el borde inferior bordados policromos de punto de cruz o a máquina con orillas recortadas, el jubón es una solapa cuadrada ricamente bordada que va sobrepuesto al hipil, y el fustán o enagua de cintura lleva encajes blancos (2011: 313. Subrayado en el original).

2 "En Yucatán este término tiene dos contenidos semánticos: el étnico y el social caracterizado en otro tiempo por la indumentaria. Mujer de origen indígena que porta de manera cotidiana el traje típico de la región (hipil, rebozo) (...) Mujer que se viste con el terno, o traje de gala mestiza, para ir a la vaquería u otra ocasión especial (Güémez Pineda, 2011: 235. Subrayado en el original).

3 "Baile de vaqueras, popular en la Península de Yucatán, que nació en las haciendas yucatecas. Después de la hierra del ganado, las mujeres -vaqueras- atendían a los invitados, y a sus esposas
} 
no sin modificaciones, a diferentes eventos sociales, culturales y políticos principalmente. Así, desde finales del siglo XIX hasta la fecha se mantiene como un elemento fuertemente arraigado a los valores y la identidad yucateca.

Del terno han derivado muchas otras vestimentas femeninas que han actualizado su empleo y lo han adaptado a circunstancias particulares, tratando de mantener los bordados como elemento de identificación del estado y de la prenda ${ }^{4}$. Esta tendencia de actualización ha expandido el empleo de estas prendas bordadas a numerosos actos, particularmente a actos políticos en los que se quiere refrendar la identidad regional y el papel de las acciones de gobierno, así las edecanes de estos eventos portarán el terno, algunas políticas lo harán igualmente, pero otras optarán por piezas actualizadas, como las blusas/hipiles (ver ilustración 1).

El terno y sus actualizaciones tienen hoy día una fuerte presencia en Mérida, que no se restringe a los acontecimientos políticos y culturales de la ciudad, pues como símbolo de la identidad yucateca ha sido incluido en el repertorio de las artesanías yucatecas que se expenden en el mercado turístico de la ciudad, mismo que presenta la oferta más amplia de productos turísticos del estado. Con esta misma idea turística, el terno está presente en las escenificaciones de las vaquerías, que el Ayuntamiento de Mérida realiza cada lunes frente al palacio municipal, y en las serenatas que se llevan a cabo cada jueves en el parque de Santa Lucía, localizado en el centro histórico de

y, como final de la fiesta, danzaban viejos sones mayas influenciados por la música española o viceversa. Los asistentes, ataviados con sus trajes de "mestizas" y "mestizos", bailaban jaranas, baile típico del que existen dos formas métricas, 6 × 8 y el $3 \times 4$. En la actualidad las vaquerías casi siempre se hacen en los corredores de los palacios o comisarías municipales y marcan formalmente el inicio de la "fiesta del pueblo" o del santo patrono. Las vaquerías suelen dar inicio avanzada la noche. Las muchachas de la localidad y de otras comunidades vecinas asisten vestidas de vaqueras: esto es con el terno y llevando en la cabeza un sombrero adornado con flores y/o cintas y un espejito" (Güémez Pineda, 2011:337-338. Subrayado en el original).

${ }^{4}$ Para agilizar la redacción del presente documento, de ahora en adelante, cuando nos refiramos al terno incluiremos sus actualizaciones y derivados. Por actualización entendemos, el empleo de nuevos colores, texturas y telas estampadas que han sustituido a las telas blancas de los ternos, la inclusión de colores y por derivados entendemos, ciertas modalidades de vestido, especialmente las blusas que asemejan la estructura básica del hipil. Vale la pena señalar que en Yucatán la palabra que se emplea para referirse a la vestimenta femenina típica de la región es hipil, y que la versión festiva de esta prenda se denomina terno, misma que queda incluida en nuestro análisis. Los términos hipil y wipil provienen de la misma palabra wipilii (náhuatl). En Yucatán la w fue eliminada para evitar la cacofonía con la segunda persona del singular en maya yucateco, que diría $u$-ipil, que significa tu hipil (Patrón Rejón, 2003). 


\section{Mérida.}

El traje regional también está exhibido en las vitrinas de dos museos de la ciudad: el Gran Museo del Mundo Maya de Mérida (el mayor museo de Mérida) y el Museo de la Ciudad. Su presencia en estas vitrinas destaca el traje regional de las mujeres y minimiza el traje regional masculino. Su exhibición en estos dos espacios es parte de la construcción y definición de lo yucateco, como lo es también el Museo de la Canción Yucateca.

Ilustración 1. Modelo de blusa tipo hipil.

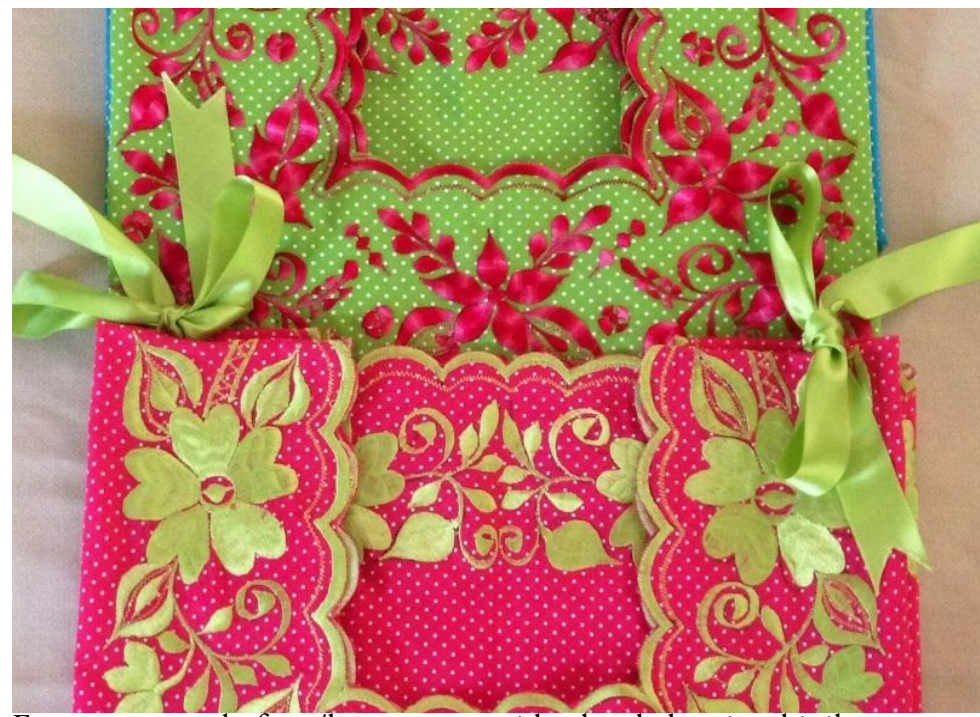

Fuente: www.clasf.mx/hermosos-vestidos-bordados-tipo-hipil-yucatecoen-méxico-6585273/

En lo que toca a la versión masculina del traje regional, esta se ha materializado en la guayabera yucateca, prenda de origen caribeño, aparentemente de Cuba, que fue adoptada desde mediados de la década de los cincuenta del siglo pasado y que ha sido a nivel nacional un emblema y símbolo de la región, especialmente de Mérida. En este contexto el propósito de este artículo es el de dar cuenta de algunos aspectos de las dinámicas que el traje regional, compuesto por ternos y guayaberas, así como por sus derivados y actualizaciones, ha manifestado en el marco de la construcción identitaria de Yucatán, destacando 
sus discordancias internas, así como su inclusión diferenciada en el mercado turístico y no turístico de Mérida 5 .

Para ello hemos dividido el trabajo en cuatro partes, en la primera abordamos los procesos de construcción identitaria y la posición del vestido en estos. Con base en esta perspectiva ubicamos al vestido regional como soporte de la identidad yucateca, entendida como una identidad menor en su oposición a la identidad nacional, que constituye una identidad mayor.

En la segunda parte hacemos una revisión relacionada con la manera en la que han sido abordadas las artesanías en el contexto del estado de Yucatán, brindamos algunas ideas en torno a las mismas y contrastamos éstas con la noción de etnomercancía, poniendo especial énfasis en los ternos y las guayaberas. Con ello queremos ubicar a la vestimenta yucateca en un espacio de consumo y en su papel como bien cultural identitatrio del estado.

En la tercera, analizamos la dinámica contemporánea de la vestimenta yucateca, considerando su oferta en el mercado meridano, y presentamos lo que creemos son las principales diferencias en torno a la vestimenta femenina y masculina en cuanto a su significado e implicaciones sociales y culturales.

Por último, en el cuarto apartado recuperamos algunos de los aportes de este trabajo y dejamos abiertas ciertas preguntas para ahondar en el tema.

\section{El traje regional yucateco como identidad menor}

Una de las bases de la discusión, que hoy día se da por sentado, es que las identidades "nunca están unificadas y, en tiempos modernos recientes, están fragmentadas y fracturadas; nunca son construidas de manera singular, sino que se construyen de manera múltiple a través de la intersección de diferentes y antagónicos discursos, prácticas y posiciones” (Hall, 1996: 4). En esta

\footnotetext{
${ }^{5}$ Este trabajo se basa en información de campo recopilada en entrevistas formales e informales a 30 dependientes de tiendas artesanales en los corredores turísticos de Mérida y en otras tiendas fuera de ellos, en 2014, 2015 y 2016. En 2018 se revisitaron 10 de esos sitios y se entrevistaron a tres dependientes, específicamente de tiendas relacionadas con la venta de hipiles y guayaberas. Se realizaron observaciones analíticas tanto a las vitrinas físicas de las tiendas, como las vitrinas virtuales (portales de internet) para actualizar, en su caso, la información referente a las artesanías. Esta estrategia sigue la propuesta de Mariné-Roig para el caso de Barcelona (2011). Igualmente se realizaron seguimientos hemerográficos que dan cuenta del uso de las guayaberas y de los ternos en eventos políticos y sociales, y asistimos a eventos que celebran el uso del traje regional yucateco.
} 
dirección no son ni han sido fijas en el tiempo ni en los diferentes espacios y contextos en los que significan y dan sentido a prácticas sociales y culturales.

Hall añade que las identidades se fundamentan en cuestionamientos sobre el uso de los recursos de la historia, el lenguaje y la cultura en el proceso de construcción de quiénes llegamos a ser, además de quiénes somos. Así, las identidades se construyen tanto dentro del discurso y como producto de lugares y contextos históricos e institucionales, como a través de la diferencia y no fuera de ella (1996: 4).

Larrain (2004) considera tres elementos para dar cuenta de los límites en la definición de las identidades, estos son:

a. identificación con categorías sociales compartidas;

b. producción/consumo de elementos materiales que dan cuenta de la proyección de su propia imagen en ellos, con lo cual crean distinción, y c. reconocimiento de otros modos de vida, lo que genera contraste y límite.

En concordancia con Hall (1996), estos elementos deber ser vistos de manera dinámica, cambiante y negociada en el contraste con otras identidades.

Algunas de las manifestaciones visibles de la cultura material son referentes de expresiones culturales menos visibles y también más amplias (Chambers 2010), en este sentido pueden ser referentes de la identidad, constituyéndose como elementos que significan y dan significado a los propios artefactos, a sus productores y a sus consumidores. Así, el vestido concreta la identidad y la hace asequible al propio grupo.

Saltzman plantea que "la vestimenta [en su conjunto] es un sistema de signos cuya articulación constituye sentido” (2007: 117). Continúa señalando que "el vestido conforma hábitos y costumbres que se consolidan en normas vestimentarias típicas de una determinada cultura o grupo" (Saltzman, 2007: 117). Así, "[e]l vestido siempre significa algo y transmite información vital en relación a los hábitos, el grupo étnico al que el individuo pertenece, su grado de religiosidad, independencia, originalidad o excentricidad, así como su conceptualización sobre la sexualidad y el cuerpo" (Squicciano en Saltzman, 2007: 123).

La velocidad de la dinámica de las trasformaciones que el vestido señala es muy importante, "[n]o obstante, y salvo en las culturas primitivas o en aquellas que tienen un fuerte arraigo en las tradiciones, la indumentaria se presenta como un sistema de signos cuyos códigos se mutan casi a la par de la 
sociedad" (Saltzman 2007: 127). El cuerpo del usuario contextualiza al vestido y el cuerpo vestido se contextualiza a partir del escenario en que se presenta.

Complementando esta idea consideramos la aproximación de Martí, quien, como parte de la presentación social del cuerpo, entiende la indumentaria como un aspecto intrínseco de esta y como mecanismo de control social, "[1]a imposición de la indumentaria ha sido siempre un elemento de capital importancia en la forja de sistemas de dominación” (Martí, 2012: 11). Por ello, la conformación de los trajes nacionales y regionales debe ser vista como parte de proyectos políticos más amplios para la construcción de las identidades nacionales o regionales (Valenciano-Mañé, 2012) y, como consecuencia, un terreno de disputas y conflictos, como bien relatan Otzoy (1992)y Hendrickson (1997) para el caso de Guatemala.

Muchos antropólogos han entendido al vestido como uno de los elementos culturales sobre los que se asienta la identidad cultural (Eicher, 1995; Bartolomé y Barabas, 1999; Millet Cámara y Quintal Avilés, 1994; Garza Navejas, 2005; Ruiz Ávila, 2012). Se trata de uno de los rasgos culturales más visibles y obvios con los que los límites grupales se pueden establecer, entre un nosotros que porta o usa determinado tipo de atuendo, y unos otros que no lo hacen, todo ello con las implicaciones económicas, políticas y sociales que conlleva.

En el caso mexicano, la indumentaria nacional se ha centrado en las imágenes de la china poblana y del charro. Su vestido es referencia a nivel nacional, su empleo se ha realizado con base en una selección particular de ciertos atributos que interesaban destacar en la construcción del México posrevolucionario, y que por ende dejaba de lado de la imagen de nación a las regiones y sus dinámicas internas particulares, pero también las relaciones entre la llamada provincia mexicana y el centro de México, mismo que imponía e impone la imagen nacional (Pérez Montfort, Villa, Novelo y Urzúa, 2009). Pérez Montfort (2007: 123-124) señala que el cuadro estereotípico nacional lo componían el charro y la china poblana bailando el Jarabe Tapatío, se trataba de la integración de tres elementos que se habían desarrollado por separado y que desde fines de la segunda década del siglo XX y principio de los años veinte de ese mismo siglo, representaba el cuadro típico nacional. Esta situación tuvo y tiene un papel relevante en la promoción turística de México en el plano internacional. 
Una aproximación que contribuye a entender la dinámica de la construcción conflictiva de las identidades nacionales y regionales es la que proponen Deleuze y Guattari (1968: 16-18), quienes, analizando la producción literaria, distinguen la existencia de una literatura menor caracterizada por su desterritorialización, su inmediatez política y el carácter colectivo de su enunciación. Desde esta aproximación, y de manera análoga, situamos a la identidad yucateca como una identidad menor que se construye y reproduce dentro de una identidad mayor, la identidad nacional mexicana, con la que se contrapone y desde la cual construye caminos alternos que le dan su especificidad, pero con la cual mantiene una relación de subordinación ${ }^{6}$.

Abundando un poco más en esta aproximación podemos ver que la primera característica señalada por Deleuze y Guattari (1986) refiere al espacio marginal en la que se desenvuelve, en este caso, se trata de un territorio, el yucateco, alejado de las decisiones políticas nacionales, con las que se ha enfrentado incluso en más de una ocasión. La segunda tiene que ver con que el accionar individual siempre expresa una posición política, así, el traje regional yucateco opera como una manifestación de las expresiones políticas regionales construidas como un proyecto político propio. La tercera refiere a que su enunciación es siempre desde la colectividad, se trata entonces del pueblo yucateco hablando, a través de la indumentaria, de su especificidad dentro de un contexto que lo envuelve y lo domina. El traje regional yucateco, como uno de los soportes de la identidad yucateca, se manifiesta hacia el exterior como un contrapeso a la indumentaria hegemónica que mantiene a la china poblana y al charro como referentes estereotípicos de la identidad nacional.

Para el caso de Yucatán, el terno y la guayabera se consideran como una expresión de la identidad yucateca, misma que se promueve por diversos medios e instancias. A diferencia de Campeche y de Quintana Roo, que son parte del territorio maya, en Yucatán el traje tradicional típico de la mujer es el terno (ver ilustración 2). Es una prenda que distingue a la mujer yucateca sin importar su clase social o sus características étnicas, es asumido como traje representativo del estado por la generalidad de la población. Según Millet y Quintal (1994) se trata, curiosamente, de la adopción de una prenda de los dominados por parte de los dominadores. En el mismo escrito los autores

\footnotetext{
${ }^{6}$ Ayora Díaz (2010) ya ha empleado esta misma idea en su análisis de los recetarios de cocina yucatecos, lo mismo que Yanes (2014) para su análisis de la producción literaria maya en Guatemala.
} 
Ilustración 2. Traje tradicional típico femenino

\section{E[Terno Tucateco}

\section{El terno es un traje típico de gala y como su nombre lo indica consta de 3 piezas}

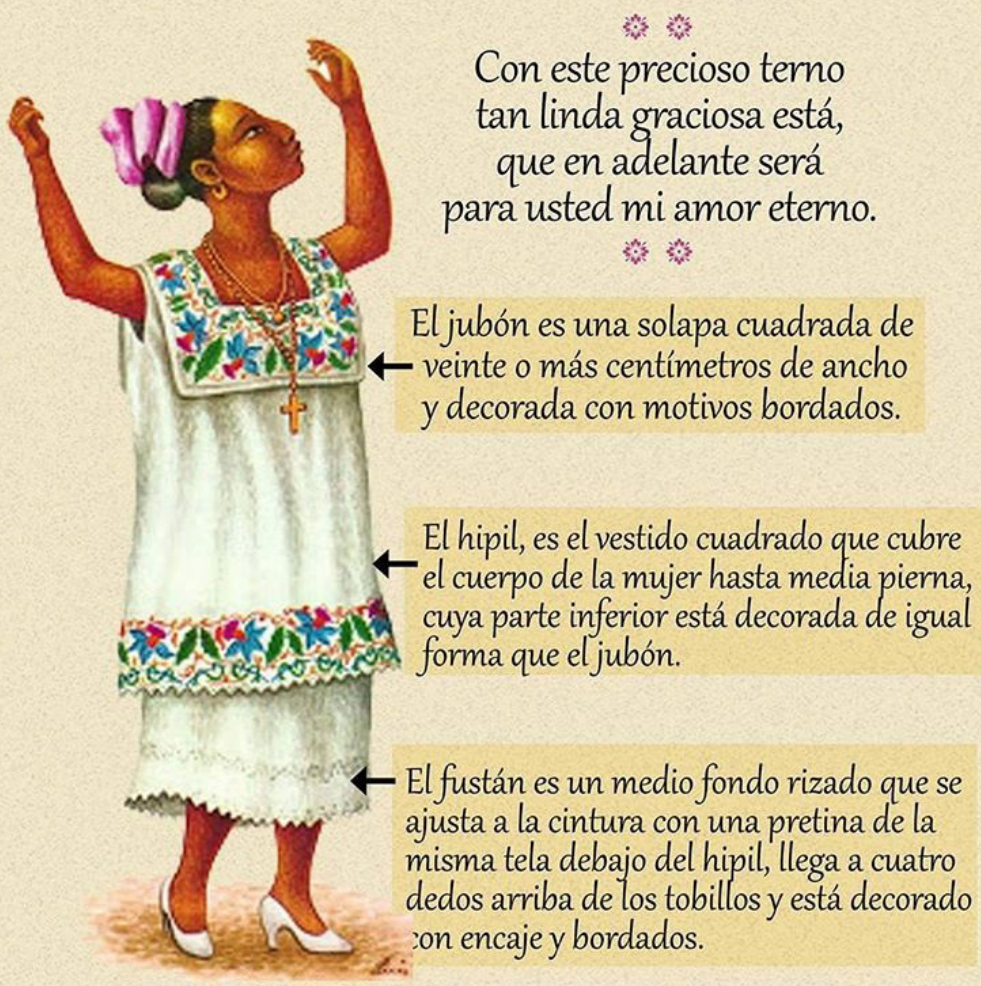

Fuente: http://danzatotal.blogspot.mx

Fuente: http://danzatotal.blogspot.mx

señalan que la adopción primera fue el hipil, que identifican como indígena y cuyo uso se limitaba únicamente al hogar ${ }^{7}$. Posteriormente, basado en el hipil se creó el terno, mismo que se generalizó y que, con ciertas variantes, fue adoptado durante el siglo XIX como el vestido representativo de las yucatecas,

\footnotetext{
${ }^{7}$ Según Hernández Fajardo (1944), el traje de los indios fue impuesto por los españoles durante la conquista suplantando a lo que él llama el traje aborigen.
} 
de hecho, el terno representa para los autores el vestido de la identidad yucateca femenina.

En el caso del hipil, Rejón Patrón señala que es el "sustento de la definición de lo que es la femineidad maya. De la misma manera que la milpa define al hombre maya" (2003: posición 3890 Edición Kindle). Ahora bien, en lo que atañe al presente trabajo, importa recuperar una doble idea que plantea la autora en relación con el hipil y el terno pues, según ella, ambos son emblemas de la identidad maya y al mismo tiempo, la última prenda es un símbolo de la identidad regional (Rejón Patrón 2003: posición 4000 Edición Kindle).

Las ideas antedichas dan cuenta de la conformación de uno de los soportes de la identidad regional yucateca, se trató de la imposición de una indumentaria que se propuso y adoptó atravesando las diferencias culturales, sociales, económicas y políticas a nivel regional, como parte de un proyecto político que delimitó y diferenció cabalmente las distancias entre Yucatán y otras regiones de México, particularmente del centro del país. El significado del terno se expandió y sinecdóticamente se convirtió en un referente de la identidad regional. Así, es posible observar los bordados de los ternos adornando invitaciones, festejos, anuncios y numerosos grupos de objetos como tazas, bolígrafos, libretas, platos, saleros, entre otros. Igualmente se han elaborado otros productos que siguiendo los patrones del terno ostentan su peculiaridad regional, como bolsas de mano, estuches para lápices y bolígrafos, entre otros. Todo ello para acentuar la identidad regional y no solamente para enmarcar la identidad femenina yucateca, pero también para refrendar la identidad yucateca, construida en oposición a la identidad nacional y a sus soportes simbólicos, la china poblana y el charro (Pérez Montfort, Villa, Novelo y Urzúa, 2009).

La contraparte del traje regional o típico femenino de Yucatán no es la filipina ${ }^{8}$, a pesar de que se reconozca que el acompañante masculino de la mestiza -la que porta el traje regional- debe utilizar una prenda de ese tipo. La filipina ha sido parcialmente soslayada y suplantada por la guayabera, mientras que la guayabera ha sido sobreestimada y reconocida como la prenda 8 "Camisa recta de tela delgada (algodón o popelina), blanca, con botones al frente, manga larga y cuello cerrado y alto y se lleva por encima de los pantalones. En Yucatán la usan los bailadores de jarana y meseros de algunos bares y restaurantes de comida regional" (Güémez Pineda, 2011: 165). Complementan su atuendo de baile, un pantalón blanco, largo, generalmente con valencianas, un sombrero de palma, un pañuelo grande que sobresale de una de las bolsas laterales del pantalón y unas alpargatas de cuero denominadas en maya xanab k'éewel. 
que enmarca la identidad masculina yucateca. A pesar de que su origen sea abiertamente reconocido como foráneo e identificado con el Caribe, en especial con Cuba, su apropiación ha creado, para Yucatán y los yucatecos, un imaginario que las tipifica como algo genuinamente yucateco. Por ello, la propaganda comercial relacionada con esa prenda enfatiza mediante su territorialización, su característica de ser yucateca, se promueve, por tanto, no a la guayabera en abstracto, sino a la guayabera yucateca. En contraste, no se necesita señalar que el terno es yucateco, pues se asume como tal.

En el siguiente apartado revisamos el concepto de artesanías y lo contrastamos con el de etnomercancías, para situar al terno y a la guayabera dentro de esta dinámica. Analizamos algunas de las estrategias que se presentan en el mercado meridano en relación con la promoción y venta de estas artesanías/etnomercancías que estamos considerando en el análisis.

\section{El traje regional yucateco entre artesanía y etnomercancía ${ }^{9}$}

La promoción e impulso de la producción artesanal como uno de los mecanismos que han procurado mejorar las condiciones económicas de ciertos sectores de la población, especialmente de grupos indígenas y de poblaciones rurales, representa una fuente importante de ingresos y de ocupación para la población nacional, y es vista al mismo tiempo como uno de los anclajes de la identidad nacional, y como una manera de "vender México" al mercado turístico del país.

No obstante, la artesanía no debe mirarse como objeto ensimismado (García Canclini, 2007), sino que -coincidiendo con Novelo (1981) - el entendimiento de lo que es la artesanía debe vincularse con las siguientes preguntas y sus respectivas respuestas: quién las produce, cómo las producen, para quiénes la producen, para qué se producen y cuándo se producen. Estas preguntas nos muestran las relaciones que detentan con los seres humanos, el

\footnotetext{
${ }^{9}$ Yucatán es uno de los tres estados de la Península de Yucatán, en México. Para 2015 contaba con 2, 097175 habitantes. En 2010, 84\% de la población habitaba en zonas urbanas mientras que el restante $16 \%$ lo hacía en zonas rurales. Yucatán ocupaba el segundo lugar con mayor población de hablantes de lengua indígena de tres años o más, de los cuales un $98.14 \%$ habla maya. La división ocupacional del estado revela que únicamente $9.27 \%$ de la población se ocupa en actividades agropecuarias, mientras que prácticamente el resto lo hace en la industria, en el comercio y en diversos servicios, o se desempeńa laboralmente como funcionario, profesionista técnico o administrativo.
} 
entorno natural y social, y la herencia tecnológica, artística y cultural (Novelo, 1976 y 1993).

Las artesanías han sido estudiadas en el territorio nacional mexicano desde diversas perspectivas, no intentaremos pormenorizar estos estudios, pero parece importante dedicar algunas líneas sobre ciertas ideas con las que se ha abordado el estudio de las artesanías. Numerosas páginas se han dedicado a discutir lo que se concibe como artesanía, sus límites y relaciones con el arte popular (Álvarez Noguera, 1969; Martínez Peñaloza, 1982; Capello Héctor, 2008). Encontramos diversas definiciones que enfatizan lo que podríamos llamar las condiciones objetivas de las artesanías, cosas tales como los materiales empleados, las técnicas utilizadas, la organización del trabajo, la creatividad, la relación con objetos prehispánicos, su ubicación en los mercados, el origen de la inspiración para la creación, su relación con un territorio, todo ello considerando las características atribuidas al objeto y en el marco de su producción y su contexto sociocultural (Hernández-Díaz y Zafra 2005; Novelo 1993, García Canclini 2007). Nos encontramos también, en otro orden de cosas, con los discursos alrededor de ellas, estos consideran su materialidad y su producción, destacando sus significados y símbolos como ejes articuladores importantes en la construcción del estado nacional y consecuentemente de la identidad nacional (Pérez Montfort, 1994; Rotman, 2011). Estos discursos no olvidan que las artesanías se ofrecen prioritariamente en el mercado turístico y, por tanto, legitiman estos productos otorgándoles un sello de autenticidad (Bayona Escat, 2013; Arroyo, 2006; De Mello y Ciliane Ceretta, 2015; Rivera Cruz, 2008) y más específicamente se aproximan a ellas como souvenires (Estévez González, 2008; Mariné Roig, 2011). Comprar artesanías es una sinécdoque de comprar un pedacito de México.

Tanto a nivel nacional como regional, e independientemente de las características atribuidas a las artesanías (material, manufactura e iconografía), ubicar estos objetos en el marco de una tienda artesanal los convierte en tales. El turismo las concibe de esta manera, más allá de los fines para los que haya sido elaborada (ornamento o fines utilitarios).

En lo que refiere de manera más específica a Yucatán, una de las primeras referencias antropológicas sobre las artesanías yucatecas la encontramos en Redfield y Villa Rojas (1962), en este trabajo señalan que la principal artesanía se basa en el empleo de la fibra de henequén para elaborar ciertos productos, 
tales como hamacas, sabucanes y mecapales. El bordado era practicado con telares de cintura, pero ya se había abandonado. Curiosamente clasifican el vestido femenino (hipil) bajo la categoría de "vestido", quedando fuera de las artesanías, contrariamente a lo que sucede hoy en día. Redfield y Villa Rojas no dedican más que un párrafo a las artesanías, situación que se reproduce en el trabajo más amplio de Redfield, Yucatán, una cultura de transición (1945), donde hubiéramos podido esperar un capítulo que dijera algo así como, de artesanía a mercancía, para dar cuenta de su continuum folk-urbano.

El trabajo de Alice Littlefield (1976) puede considerarse como el trabajo pionero de la antropología en el análisis de las artesanías en Yucatán. La autora aborda la producción de hamacas, dando por descontado que se trata de una artesanía, como una producción de tipo maquila y estudia cómo se articula esta producción al desarrollo económico capitalista, advirtiendo la dependencia de las artesanías del mercado turístico (1976: 213).

En esa misma vía, pero con otros instrumentos analíticos, Villanueva Villanueva (1983 y 1996) vincula las artesanías y su proliferación en Halachó, Yucatán, con los problemas agrícolas, y ve en la confección de productos de guano y batas bordadas una alternativa económica promovida por programas estatales a los que muchas familias recurrieron en su momento para paliar su precaria situación económica. No discute el término artesanía, pero, según su argumentación, se distinguiría por el empleo de mano de obra local y familiar, añadiendo que no necesariamente incluye tecnologías o productos locales. La autora en determinados momentos refiere a estos objetos como "productos artesanales", lo que nos lleva a pensar que es justamente en el mercado, en particular en el mercado turístico, donde un producto se realiza como artesanía y no así en su proceso productivo, aunque éste pueda ser caracterizado con propiedad como manual y elaborado con técnicas simples.

Otro trabajo realizado en el mismo lugar, Halachó, Yucatán, pero con otro tipo de artesanías, define a las mismas de la siguiente manera:

las artesanías tradicionales son aquellos bienes realizados para el consumo doméstico y/o ritual, siendo objetos portadores de un valor histórico, cultural, utilitario o estético y que cumplen con una función socialmente reconocida, 
realizados por el artesano, individual o colectivamente, mediante técnicas simples (Angelotti Pasteur, 2004: 26).

Complementa el mismo autor esta definición con la de artesano, que entiende como "aquel individuo portador de una cultura, que mediante el dominio de una técnica predominantemente manual y con el apoyo de unas herramientas primarias, transforma la materia con la finalidad de crear objetos socialmente útiles" (Angelotti Pasteur, 2004: 26).

Desde nuestro punto de vista dos cosas quedan pendientes, por un lado, la idea de que hay artesanías no tradicionales y, por el otro, la continua oposición entre lo tradicional y lo moderno como parámetro determinante para conceptualizar la artesanía.

Esto puede encontrarse en la definición de Rasmussen, Arroyo y Terán (2010) que, de manera más directa por el carácter de la publicación, pues se trata de una obra de divulgación, señala lo siguiente: "entendemos por artesanía, piezas - de bordado, piedra, barro, metales, madera, etc.- hechas a mano, con o sin la ayuda de instrumentos manuales o eléctricos, que conservan una identidad que permite identificarlos como yucatecos o mayas" (Rasmussen, Arroyo y Terán, 2010: 11). Como se puede apreciar claramente, la definición se aleja de la composición material del objeto para situarse en el significado del mismo. Tampoco se aprecia un intento de hacer de la artesanía un objeto tradicional.

Estas posiciones pueden utilizarse como punto de partida para dar cuenta de dos aspectos importantes desde nuestra aproximación, la primera, hay artesanías modernas que pueden o no cumplir con las condiciones de producción y materiales para su definición, y la segunda, que la dimensión simbólica e identitaria de las mismas se convierte en un elemento central para que determinados productos se vendan como artesanías, más allá de sus componentes o procesos productivos. Tal es el caso de los ternos y las guayaberas.

Los discursos oficiales sobre las artesanías de Yucatán se ajustan a esta visión, lo que puede observarse en la siguiente conceptualización de artesanías del Gobierno del Estado de Yucatán: 
En todo Yucatán se elaboran artículos de los más diversos materiales, diseños y colores, que además de ser útiles, aportan belleza y elegancia a nuestro entorno: joyería de filigrana en oro y plata; artefactos de carey, concha, caracol, madera y piedra tallada; vasijas de barro; instrumentos musicales; tejidos de fibra de henequén y de algodón; bordados, aplicaciones de encaje, calados, y punto de cruz; ternos, guayaberas y hamacas; sombreros de paja y de palma del jipi; petates de junco y bejuco; bolsas y zapatos de piel.

Existen otras ramas artesanales de incipiente generación que también nos dan muestra del gran talento artesanal de Yucatán. Destacan la pintura popular, juguetería, reciclado y la herrería, que formó parte de la grandeza de las edificaciones antiguas. La elaboración de objetos de papel y hoja de elote son actividades en pleno desarrollo (http://www.yucatan.gob.mx/?p=artesanias. Consultado el 7 de mayo de 2018).

Estas mismas ideas se mantienen en trabajos como el de Rassmusen, Arroyo y Terán (2010), que incluyen como artesanías a productos elaborados con materiales tales como la madera, el bejuco, el henequén, el guano, la piedra, así como técnicas específicas como la alfarería, la talabartería, la joyería y, más allá de estas, el reciclaje, del que especifican, papel, llantas y chatarra, así como bolsas de botanas y latas de aluminio.

Podemos apreciar entonces que hay actividades artesanales como el reciclado y la pintura popular que definitivamente no forman parte de las artesanías tradicionales pero que ahora se han incorporado a ellas, a tal punto que son parte integral no solo de la recreación de elementos y procesos antiguos recuperados, sino de tendencias a nivel global. Lo mismo podríamos decir de ciertos artículos suntuarios, como señala Tun Tun (2013), o del tallado de madera en Chichén Itzá (Castañeda, 2009 y Figueroa Gómez, 2014).

La promoción activa de las artesanías yucatecas ha llevado a las autoridades estatales a realizar concursos de producción artesanal, al reconocimiento y celebración del día del artesano y la artesana (30 de mayo), a la puesta en marcha de un evento denominado "La semana de Yucatán en México" y a re-lanzar la guayabera como una prenda de vestir moderna que compita con las grandes creaciones internacionales en materia de vestido y moda (ver Ilustración 3). 
Ilustración 3. El gobernador del estado de Yucatán (2012-2018), entregando un reconocimiento en la celebración del día de la guayabera 2018 .

\section{Con Día de la Guayabera, se fomenta uso de prenda típica.}

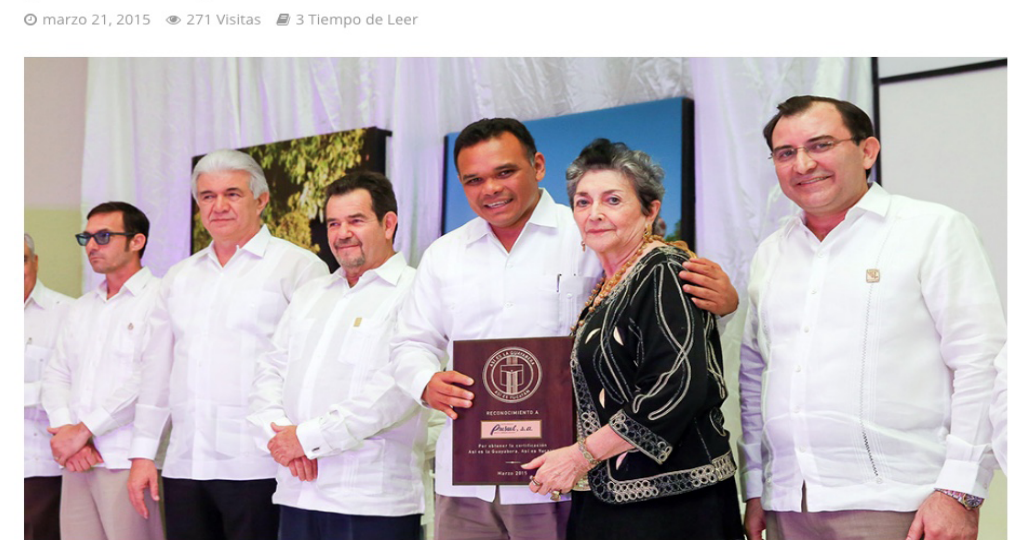

Fuente: http://www.mipuntodevista.com.mx/con-dia-de-la-guayabera-sefomenta-uso-de-prenda-tipica/

A partir de la configuración de los productos en venta y que toman el apelativo de artesanía, podemos señalar que en Yucatán se producen artesanías tradicionales, en oposición (aunque no definidas por) a las artesanías modernas. Que las artesanías yucatecas se definen tanto por ciertos procesos productivos, fundamentalmente manuales y con tecnología simple, pero que también incluyen otros productos simplemente por el material con el que se elaboran, material que está ligado simbólicamente al territorio yucateco. Que los procesos de maquila e industriales quedan incluidos en la producción de artesanías, como son la producción de ternos y guayaberas. Que entre las artesanías pueden ser incluidos nuevos productos, realizados a partir del reciclado de diversos objetos, resaltando para ello la capacidad creativa y el trabajo manual de los yucatecos. Que las artesanías dan "vida a las tradiciones que identifican y enorgullecen a Yucatán”. Con esto podemos señalar que, potencialmente, muchos productos actuales y futuros tienen la posibilidad de manufacturarse como o ser convertidos en artesanías. 
Ante esta compleja situación, nos parece pertinente retomar la propuesta de Escalona Victoria (2016), sobre un cierto tipo de objetos/productos que denomina etnomercancías, entendidas como:

un objeto que tiene la apariencia de ser producto de una perspectiva cultural específica, resultado de trabajo que se supone implica un conocimiento especializado y que expresa formas de entendimiento del mundo que son también específicas de un grupo social (al que se atribuye una especificidad y una antigüedad cultural inconmensurables) (Escalona Victoria, 2016: 261).

Adicionalmente señala el carácter simbólico para representar al grupo del que proviene, tiene una apariencia étnica, auténtica y se liga a un grupo culturalmente delimitado, es "un objeto encarnado en la historia del imaginario sociopolítico en México -no de manera exclusiva- que se expresa en empresas de turismo, de desarrollo, en políticas públicas e incluso de la investigación antropológica" (Escalona Victoria, 2016: 262). Llega a esta propuesta a partir de los procesos de sobrefetichización de ciertas mercancías de "apariencia artesanal", o en otras palabras, la ubicación de éstas en diferentes regímenes de valor -como obras de arte, como piezas de museo, como productos para el turismo, entre otras-.

Sin embargo, si bien esta propuesta descentra nuestra atención de los procesos de producción y de las condiciones de producción de las mercancías, ubicando a las mismas en la circulación y el consumo, es limitante para nuestro caso, dado que los textiles a que nos referimos en este trabajo representan tanto a un grupo como el pueblo maya, como otro grupo que propiamente no lo es, pues tanto los ternos como las guayaberas son indicadores de un grupo mayor que incluye a todos los yucatecos, independientemente de su afiliación étnica. De esta manera, estas prendas son consumidas tanto por locales de diversas adscripciones étnicas, como por los turistas nacionales y extranjeros.

En todo caso, y guardando las reservas pertinentes, se tratarían de una especie de etnomercancía, que además de representar a un grupo étnico -el pueblo maya-, refiere y significa a un grupo mayor, los yucatecos. Esta posición se acerca a las ideas de Comaroff y Comaroff (2009) cuando plantean los procesos de mercantilización que los grupos étnicos han realizado en tiempos recientes con la finalidad de obtener beneficios de su propia identidad 
y filiación étnica. La diferencia central para el caso de Yucatán se refleja en los procesos de apropiación de prácticas y símbolos culturales que son arrebatados de las manos del pueblo maya.

Esta aproximación, sin embargo, tiene que dialogar con el discurso de promoción y venta de ternos y guayaberas que continuamente enfatizan el carácter artesanal de estos productos como parte de una estrategia económicomercantil e identitaria para continuar con el desarrollo de sus mercados, tanto internos como externos. En otras palabras, no es lo mismo comprar una artesanía con el carácter simbólico que lo acompaña que una prenda de vestir elaborada en la región.

\section{Ternos y guayaberas en Mérida. Tradición y modernidad ${ }^{10}$}

Concentrada en el centro de la ciudad de Mérida y en algunos sitios del norte de la misma, especialmente aquellos relacionados con la actividad turística, la oferta de etnomercancías en la ciudad es amplia e incluye, como en muchos otros destinos turísticos, tanto productos de la región como otros provenientes de otras partes del país ${ }^{11}$. La manufactura de ternos y guayaberas proviene en su mayoría de talleres de distintos tamaños ubicados en distintas poblaciones del interior del estado de Yucatán, un caso típico es el de Tekit, una población que concentra un número significativo de talleres y emplea por igual a una gran cantidad de pobladores.

El consumo de etnomercancías ${ }^{12}$ forma parte de las obligaciones de los turistas, por ello se ha dado la proliferación de miniaturas representativas de

${ }^{10}$ Mérida es la capital del estado de Yucatán. Según el Anuario Estadístico y Geográfico de Yucatán 2017, el municipio de Mérida contaba para 2015 con 892363 habitantes. La población económicamente activa se dedica en su mayoría a actividades relacionadas con la industria manufacturera, el comercio y los servicios. Con base en la ocupación de cuartos de hotel, la ciudad recibió en 2016 a 1262775 turistas, de los cuales solamente un 20.58\% corresponde a residentes de fuera del país. Como en muchas otras partes de América Latina y Europa, el principal atractivo turístico de la ciudad es su centro histórico, donde se concentran los servicios turísticos. En el norte de la ciudad es en la avenida Paseo de Montejo donde se reúne la oferta turística, especialmente en su segmento sur.

${ }^{11}$ La oferta de ropa típica de Yucatán se concentra en las calles 59, 60 y 62 del centro de Mérida, en las calles aledañas a la iglesia y parque en Santa Ana, y en algunas plazas comerciales del norte de la ciudad. En estas últimas tienden a encontrarse más guayaberas y menos ternos. Al parecer esto se relaciona directamente con la idea de que las plazas comerciales son una materialización de la modernidad y por ello un espacio adecuado para las guayaberas.

${ }^{12} \mathrm{Ni}$ turistas ni locales consumen etnomercancías, desde su perspectiva consumen artesanías, pero desde la lógica de este artículo y con las reservas señaladas, hemos sustituido el término 
ciertos elementos identitarios de la región: la oferta de mini-pirámides de Chichén Itzá, de mini-bateas de madera y mini-hamacas, son parte del nutrido grupo de miniaturas dispuesto para los turistas. No obstante, las guayaberas y los hipiles son un tipo de producto que se localiza en dos regímenes de valor (Appadurai, 1991). Por un lado se trata de una etnomercancía particular, ubica y comparte espacio con otras etnomercancías yucatecas y no yucatecas -estamos entendiendo por esto aquellas que se realizan con ciertos materiales y a las que apelan a ciertos componentes de la cultura material de los mayas y de los yucatecos- pero al mismo tiempo representa para la población yucateca un elemento de significación regional identitario central, a diferencia por ejemplo de los trabajos de reciclado. Es promovida y comprada como etnomercancía para y por turistas nacionales e internacionales, y es consumida y comprada por los locales como elemento de identidad regional. Por supuesto comparte esta situación con otros productos como las hamacas, pero se distancia de ellas por sus características propias, especialmente su portabilidad y su relación con el cuerpo. Cuenta con una amplia presencia social, pues viste a todas las clases sociales en distintos momentos y para diversas prácticas culturales, tales como las bodas, las celebraciones de quince años, las ceremonias de graduación y los eventos políticos, entre otros, y permite que se diseminen con menos restricciones que las hamacas.

También encontramos un mayor dinamismo en las prendas de vestir en contraste con las hamacas, puesto que su actualización se ha acelerado en los últimos lustros, inscribiéndose dentro de la lógica del gusto local y con influencia de la moda internacional, especialmente en el caso de las guayaberas.

El centro histórico de Mérida constituye el espacio privilegiado donde los ternos y las guayaberas se encuentran vis a vis con otros productos artesanales de los que se distinguen y se complementan. Se distinguen, pues fundamentalmente se ubican en tiendas especializadas en "ropa típica", y se complementan debido a que el centro es interpretado por locales y extranjeros como uno de los puntos de mayor atracción turística de la ciudad, porque en él reside la identidad de la ciudad (Urzaiz Lares, 2011).

La multiplicación de diseños es constante, en las vitrinas que exponen estas prendas podemos observar una multitud de colores y diseńos. Solapas y blusas Frida pasan a formar parte de la oferta y del repertorio de alternativas que se 
ofrecen por igual a turistas y yucatecos. Pedro, un experimentado vendedor de ropa típica yucateca de una de las tiendas de artesanías del centro de Mérida, nos señaló que las prendas yucatecas se pueden distinguir fácilmente a pesar de su modernización, tres elementos las distinguen para el caso femenino: que las prendas tengan algún bordado típicamente yucateco -flores en su mayoría-, que presenten deshilado o alforzado. No fue tan explícito para el caso masculino pues no hay guayabera sin alforzas, así como no hay guayaberas con deshilados, sin embargo, ahora vemos guayaberas con bordados que asemejan a los presentes en los ternos. ${ }^{13}$

Pedro no solamente es vendedor, sino que diariamente porta una guayabera clásica, aquella que consta de alforzas con cuatro bolsas al frente. Las tiene en diferentes colores y son parte de su atuendo cotidiano. Su esposa emplea parte de su tiempo en la confección de hipiles para niñas, además que emplea una reciente técnica para decorar los hipiles, reproduciendo los patrones de bordado de los mismos con pintura, en vez de bordado.

Nos comenta también que la actualización de las guayaberas tiene que ver con el incremento del alforzado para las presidenciales, y la inclusión de vivos de color tanto en estas como en las clásicas. Según él, esto se debe a la demanda de los jóvenes que quieren asistir a las bodas y a otros eventos de importancia donde la guayabera tiene un papel relevante y sancionado positivamente ${ }^{14}$.

Estos movimientos de actualización de las prendas yucatecas tienen que ver con la necesidad de continuar ampliando una oferta que sea atractiva. Mientras las blusas/hipil convierten a las mujeres en "mestizas express", como señaló Luis, vendedor de una de las tiendas artesanales del barrio de Santa Ana, Pedro comenta que se trata de "modernizarlas para los jóvenes". En ambos casos se trata de procesos que buscan ampliar el mercado, pero también

\footnotetext{
${ }^{13}$ Se suele señalar a ciertos materiales como típicamente yucatecos, cuando se hacen con henequén, bejuco, palma, jícara, jipijapa, coco, madera y barro (Medina Várguez, 2016).

${ }^{14}$ Vale la pena señalar que, para el tercer debate de la campańa presidencial realizado en Mérida el 12 de junio de 2018, el actual presidente de México, Andrés Manuel López Obrador quería usar una guayabera pero fue disuadido, "yo quería ir de guayabera mañana, pero me mayoritearon, los otros candidatos opinaron que de taje (sic) y corbata, que se me hace, con todo respecto, algo contrario a la idiosincrasia del pueblo yucateco, porque se usa la guayabera, siempre voy a Yucatán con guayabera, es más cómoda, se apega más al clima, es la ropa pues que se debe usar" (Redaccion AN, 2018)
} 
fortalecer la identidad regional manteniendo el gusto por portar las prendas típicas en diversas actividades socialmente significativas para los yucatecos.

Claudia, una joven dependiente de otra tienda de artesanías en el centro, nos comentó que las blusas bordadas tipo hipil permiten que las mujeres gasten menos, pues el costo de un terno puede alcanzar un precio de más de 25000.00 pesos, y son pocas las mujeres que pueden acceder a ellos. La blusa bordada tipo hipil les permite conservar los rasgos típicos del hipil y, al mismo tiempo, que puedan usarse con pantalones de mezclilla, faldas o pantalones cortos, lo que otorga mayor versatilidad a la prenda y mantiene por lo menos el bordado, uno de los rasgos que hacen a esta una prenda típica de Yucatán.

Llegado a este punto nos parece importante llamar la atención sobre las distinciones entre la oferta de guayaberas y de ternos con otros mercados artesanales, estas diferencias tienen que ver con dinámicas propias que las prendas han desarrollado a través del tiempo. Más allá de su origen, el terno es un referente de la prenda femenina típica de Yucatán, su exhibición y oferta en el centro histórico de Mérida y su relación de cercanía con otras artesanías la convierte en tal, lo mismo sucede con la guayabera. No obstante, a diferencia de otras artesanías que no son parte del consumo de la población local (no al menos mayoritariamente) el terno y la guayabera sí lo son. Se adsvierte que en la oferta de estos productos se mantienen los dos regímenes de valor, por un lado se entiende como parte de la oferta artesanal y turística de Yucatán, pero al mismo tiempo entra a la oferta simbólica-identitaria y mercantil como una alternativa de vestimenta local y cotidiana en algunos casos y para ciertos productos, que inscriben estas prendas en el mercado de productos yucatecos (etnomercancías) consumidos por yucatecos.

Adicionalmente a los análisis académicos se pueden encontrar en el mercado muchas publicaciones de divulgación que, a la par de su presencia en internet, tienen por objetivo dar a conocer la producción artesanal de Yucatán. Destacan las publicaciones de la casa editorial yucateca Dante, que ha elaborado dos de ellas: una denominada "Las artesanías de Yucatán" y otra titulada "El Bordado yucateco". Ambas publicaciones se caracterizan por brindar información general acerca de la importancia, origen, técnicas y materiales empleados en la elaboración de las artesanías, y ambas están profusamente ilustradas con numerosas fotografías. Vale la pena señalar que un volumen dedicado completamente al bordado sitúa a esta producción 
artesanal por encima de cualquier otra, en particular y desde nuestro punto de vista, por ser uno de los referentes identitarios regionales más importantes.

La presencia de las etnomercancías yucatecas en internet tiene dos caminos, por un lado, está lo que podríamos denominar la promoción relacionada con una amplia y variada selección de artículos, dentro de la gama de materiales referidos como yucatecos - fibra de henequén, guano, piedra tallada, entre otros- $y$, por el otro, una promoción más dirigida a ciertos productos que destacan en el panorama de las etnomercancías yucatecas -los ternos y las guayaberas-. Así, estas etnomercancías remiten a sitios relacionados con la promoción oficial en cualquier nivel de gobierno, o bien a páginas y sitios turísticos, mientras que las palabras guayaberas, hipiles o filipinas remiten a sitios de comercialización y venta de estos productos. Además de los sitios de venta, su ubicación en las redes sociales también es importante, sobre todo para aquellos comercializadores que no tienen presencia física en Mérida.

Ilustración 4. Anuncio comercial de guayaberas.

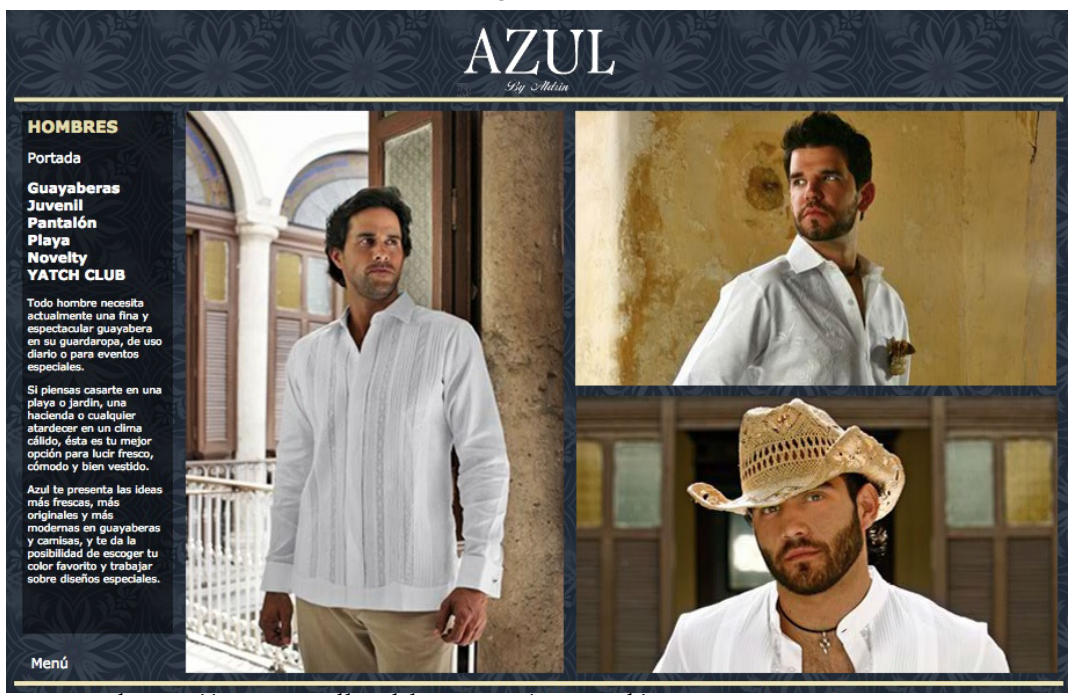

Fuente: https://www.azulbyaldrin.com/espanol/\#

Conviene distinguir la posición que las dos prendas, ternos y guayaberas, tienen en el esquema de referencia regional, la guayabera concebida como una prenda moderna: 
Todo hombre necesita actualmente una fina y espectacular guayabera en su guardaropa (sic), de uso diario o para eventos especiales.

Si piensas casarte en una playa o jardín, una hacienda o cualquier atardecer en un clima cálido, ésta es tu mejor opción para lucir fresco, cómodo y bien vestido.

Azul te presenta las ideas más frescas, más originales y más modernas en guayaberas y camisas, y te da la posibilidad de escoger tu color favorito y trabajar sobre diseños especiales.

Es así como Aldrin Ayuso desde hace más de 20 años se dedica al diseño de las guayaberas y camisas para caballero, con una amplia trayectoria en el sureste de la república mexicana, Miami, y New York, nace Azul como una propuesta nueva, fresca, vanguardista y con ideas renovadas de la tradicional y típica ropa hecha en Yucatán. (www.zankyou.com.mx/f/azul-by-aldrin-ayuso-36461. Consultado el 17de octubre de 2018) (ver Ilustración 4).

Esta visión se consolida con la creación del Día de la guayabera, que empezó a celebrarse el 21 de marzo de 2013 (ver ilustración 5) y con la puesta en marcha el año de 2018 de la primera edición del concurso "Diseña tu guayabera", promovido por la Cámara Nacional de la Industria del Vestido, Delegación Yucatán, y el programa "Así es la Guayabera, Así es Yucatán” (https://www. yucatan.com.mx/merida/primera-edicion-del-concurso-disena-guayabera.

Ilustración 5. De derecha a izquierda en el presídium se encuentra, en la segunda posición, el gobernador del estado de Yucatán del periodo 20122018, Rolando Bello Zapata.

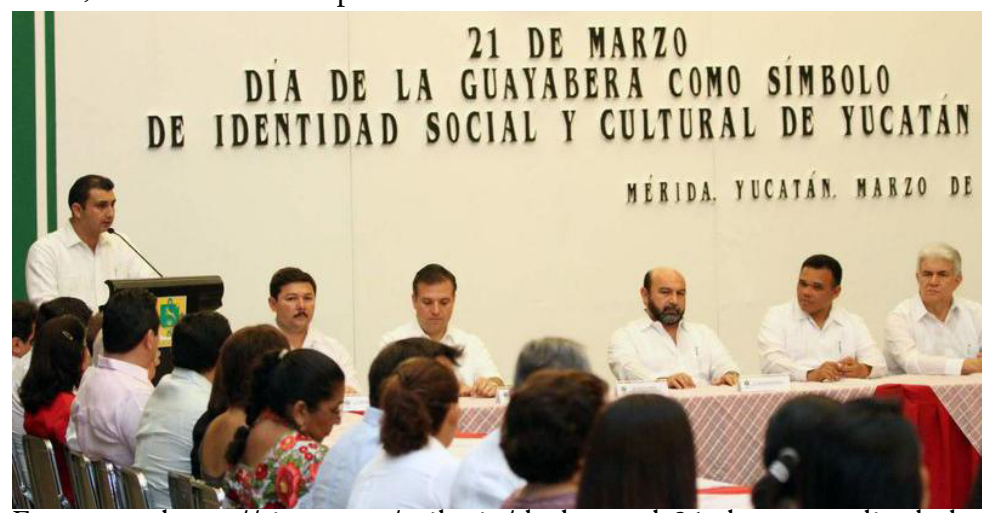

Fuente: https://sipse.com/milenio/declaran-el-21-de-marzo-dia-de-laguayabera-22007.html 
Consultado el 28 de noviembre de 2018). Estos programas son promovidos de manera conjunta por el gobierno estatal y por las cámaras empresariales, y buscan posicionar a la guayabera yucateca dentro de las tendencias de la moda a nivel internacional.

La insistencia de los gobiernos municipal y estatal, de Mérida y Yucatán respectivamente, en referirse de manera continua a ciertos productos locales como artesanías, guarda una estrecha relación con la demanda del turismo nacional e internacional de consumir productos relacionados con la región, y que por ello pueden ser considerados como auténticos. Desde principios de la década de los setenta del siglo pasado, MacCannell (1999) ya había señalado que en la modernidad, la realidad y la autenticidad están en otra parte, en otros periodos históricos; las preocupaciones de las sociedades modernas por lo natural, su nostalgia y la búsqueda de la autenticidad no son casualidad, se trata de sus vínculos con el pasado y representan de igual manera el espíritu conquistador de la modernidad. La búsqueda de la autenticidad era y es uno de los motivos principales para hacer turismo en un mundo en el que la modernidad ha diluido los significados de los objetos y de las prácticas culturales de esas sociedades, por lo que la materialidad de las artesanías y sus expresiones simbólicas representan una manera asequible de alcanzar ese mundo que ya no se puede tener. De ahí que las artesanías, como referentes materiales de la identidad yucateca, jueguen un papel central en el consumo turístico, y por ello la permanencia de este término, que apela al pasado y a la nostalgia, en el discurso dirigido a los turistas.

El terno navega en la red, como parte de una prenda tradicional, a pesar de que apelen a recursos modernos para fomentar su uso, como ocurre con el desayuno del terno que se realiza desde 2016 y que manifiesta su meta:

EL Gran Desayuno del Terno tiene como meta principal reactivar la economía de las artesanas de la zona maya. Uno de nuestros objetivos será trabajar por la conservación de la tradición del uso del terno y promoverlo en las nuevas generaciones. (elterno.com/Evento.html. Negritas en el original, cursivas nuestras. Consultado el 17 de octubre de 2017) (ver Ilustraciones 6 y 7). 
Ilustración 6. Desayuno del Gran Desayuno del terno.

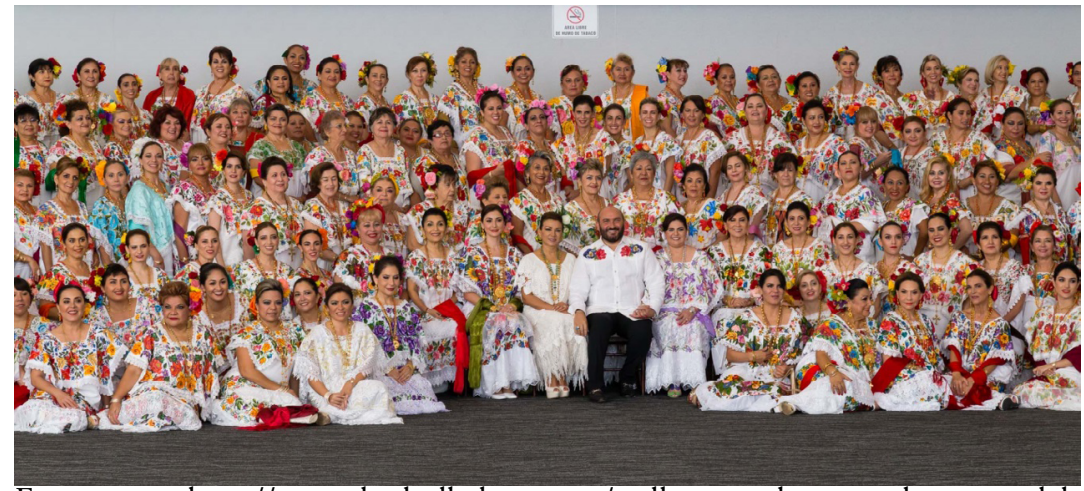

Fuente: http://www.desdeelbalcon.com/se-llevo-a-cabo-gran-desayuno-delterno/\#.XFzTn89KjdQ

A esta situación hay que añadir que, aunque el uso del terno rebasa las fronteras estatales, pues se da en todos los estados de la península, Yucatán destaca por una política activa de promoción, tanto a nivel local como turístico.

Con los párrafos antedichos podemos señalar que no hay duda que el reconocimiento local y exterior a los ternos y las guayaberas como referentes de la identidad yucateca se ha mantenido en oposición, como identidad menor, a la construcción unívoca de una identidad nacional. Esta oposición, más que enfatizar la diferencia se centra en resaltar y promover lo propio, lo apropiado y lo que está enraizado en los saberes locales.

Ilustración 7. El personaje masculino con el micrófono en mano, es el actual gobernador de Yucatán.

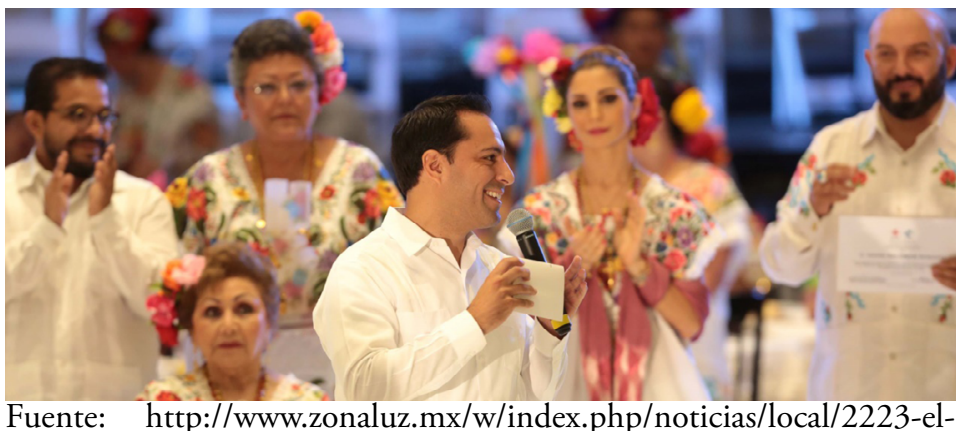

gran-desayuno-del-terno. 
Pero también, mantener el vestido típico como un referente de la identidad regional implica, como hemos visto, actuar decididamente en procesos diferenciados que apelan al sentido de tradición, unidad y solidaridad cuando las mujeres visten el terno, pues lo hacen como mujeres yucatecas que expresan sus valores y ayudan al mismo tiempo a las bordadoras y costureras de los pueblos de Yucatán. También buscan promover una imagen de los yucatecos, como agentes de cambio y modernidad, con una presencia internacional y una imagen actualizada. Se trata de dos referentes que actúan de manera diferenciada sobre dos cuerpos distintos donde la tradición tiende a centrarse en las mujeres y sus ternos y la modernidad en los hombres y sus guayaberas.

\section{A manera de cierre}

La circulación y consumo del traje regional yucateco tiene muchos espacios diferenciados que reflejan diferentes propósitos, así, en el marco de las puestas en escena de los bailes tradicionales celebra los valores y tradiciones locales; en las vitrinas de las tiendas de artesanías refiere a la autenticidad del objeto y sus vínculos con el pasado maya; en los escaparates de los museos da cuenta de la historia regional y de las habilidades técnicas y tecnologías para su elaboración, instruyendo con ello a la población y al turismo; en el plano de los eventos políticos, refiere al reconocimiento explícito e inclusivo del estado de Yucatán y a la oposición frente a una identidad nacional.

Esta situación refleja claramente la idea de que las identidades se construyen dentro del discurso, nunca fuera de él (Hall. 1996), el discurso del estado de Yucatán reconocerá sin ambigüedades que el traje regional (terno y guayabera) es el reflejo de los valores y de la identidad estatal. Su presencia continua en eventos políticos reforzará esa imagen y la comprometerá con la población local, rural y urbana; es la forma más tangible de construir un vínculo cercano con los gobernados, especialmente con aquellos que se encuentran estrechamente identificados con la indumentaria regional. Contribuye, en términos de Larrain (2004), al consumo de la propia identidad, que se ha construido en oposición a la identidad mayor, la nacional.

En el discurso turístico las artesanías tienen un lugar privilegiado, pues son representantes por antonomasia de las identidades nacionales y regionales. Son piezas auténticas de la cultura nacional y/o regional. La autenticidad domina la escena de las artesanías, y no hay lugar para las etnomercancías. 
Se da por sentado que cualquier artesanía tiene una conexión directa con la región y el territorio, por distintos motivos, ya sean los materiales, el diseño, las técnicas y la tecnología, o incluso por el simple hecho de nombrarla como tal, la convierten en un producto auténtico y representativo de la región.

Fuera de estas dos dimensiones, el empleo del concepto etnomercanía nos lleva a consideraciones de otro orden, entre ellas a entender la lógica de la producción de productos "tipo artesanal" que rememoran y acercan el pasado al presente, que dan cuenta de una visión que enaltece la tradición por encima de la modernidad y da sentido por igual al consumo. Por ello el concepto de etnomercanía refleja de mejor manera las demandas de autenticidad turística, pero también de la población local que busca permanentemente configurar su identidad y al mismo tiempo actualizarla en el marco de los rápidos procesos de transformación.

Poco importa, entonces, que los procesos industriales se hayan introducido en la manufactura del terno y la guayabera y que su producción no esté en manos de la población local, ni que los diseños expresen la creatividad de esta población (Alonzo Solís, 2015; Rubio Herrera, 2017), lo que importa es que estos mantengan la autenticidad como referente, difuso si se quiere, pero dentro de ciertos marcos aceptables para que mantengan y reflejen los valores y costumbres regionales.

Los grados de variación deben reflejar también las dinámicas de las relaciones entre las concepciones locales en torno a la posición del hombre y de la mujer. Así, el espacio asignado a la mujer se circunscribe a la tradición, a la conservación del orden y las costumbres; es una especie de cimiento sobre el que se pueden construir otras prácticas, en el entendido que estas son materia insoslayable y siempre respetable. Las variaciones del traje regional le dan más opciones de vestido a las mujeres, pero se mantienen cautas de no avanzar tanto que desfiguren la imagen de la mestiza yucateca. Incluso los espacios a los que se circunscriben están limitados, la blusa/hipil puede tener preponderancia en las políticas, pero las edecanes portarán el terno como representantes directas de la integración estatal.

En el caso de la guayabera opera un proceso bastante diferente. Quizás por su propio origen caribeño y masculino, el reconocimiento de la guayabera como el traje regional de Yucatán tiene pocos compromisos con la historia regional, con el pasado maya y con el territorio. Esto amplía las posibilidades 
de incursión a dimensiones que la indumentaria femenina no pueda alcanzar, y libra a la guayabera de ataduras a los valores ancestrales, ligándola por el contrario a un mundo más cambiante, más demandante y por ello abierto a las transformaciones.

Sin embargo, como etnomercancía, tiene que tener la congruencia necesaria para poder mantener el apelativo de producto artesanal y seguir transitando por los contextos necesarios para mantener la identidad yucateca, tanto al interior del estado y la nación, como para su desempeño como vestido y souvenir en el ámbito turístico y global.

En estas páginas hemos querido dar cuenta de la dinámica del traje regional yucateco, de sus diferentes significados y expresiones en los contextos locales y en las relaciones con la identidad nacional. Ante las rápidas transformaciones de la moda y los gustos, así como del fluir de las identidades, queda un campo extremadamente fértil para seguir avanzando en su comprensión, cuando situamos al traje regional al lado de las corrientes contemporáneas y globales que también impactan los sentires y necesidades de las poblaciones locales. ¿ En qué contextos y a que indumentaria recurrirán las yucatecas y los yucatecos para la presentación social de su cuerpo y para expresar su identidad regional en un futuro cercano?

\section{Bibliografía}

Alonzo Solís, Juan Felipe de Jesús, (2015) Dinámicas territoriales y desarrollo en un contexto de globalización económica. El caso de la industria del vestido en Yucatán. Tesis para obtener el grado de doctor en Economía, Facultad de Ciencias Económicas y Empresariales, Departamento de Economía Aplicada II, Universidad de Sevilla, 2015.

Álvarez Noguera, José Rogelio, (1969) Vidrio soplado. Ciudad de México: Organización Editorial Novaro.

Angelotti Pasteur, Gabriel, (2004) Artesanía prohibida. De cómo lo tradicional se convierte en clandestino. Mérida: Instituto Nacional de Antropología 
e Historia-El Colegio de Michoacán-Universidad Autónoma de Yucatán.

Appadurai, Arjun, (1991) "Introducción: las mercancías y la política del valor", en Arjun Appadurai (editor), La vida social de las cosas. Perspectiva cultural de las mercancías. Ciudad de México: Consejo Nacional para la Cultura y las Artes y Grijalbo. pp. 17-87.

Ayora Díaz, Steffan Igor, (2012) Foodscapes, Foodfields and Identities in Yucatán. Nueva York: Berghahn Books.

Bartolomé, Miguel Alberto y Alicia Mabel Barabas, (1999) La pluralidad en peligro. Procesos de transfiguración y extinción cultural en Oaxaca (chochos, chontales, ixcatecos y zoques). Ciudad de México: Instituto Nacional de Antropología e Historia e Instituto nacional Indigenista.

Bayona Escat, Eugenia, (2013) “Textiles para turistas: tejedoras y comerciantes en los Altos de Chiapas", en PASOS. Revista de Turismo y Patrimonio Cultural. Volumen 11, número 2, pp. 371-386.

Capello, Héctor Manuel, (2008) "Las orientaciones del arte popular y su influencia en la identidad y carácter cívico-político en México”, en Raúl Béjar y Héctor Rosales (editores), La identidad nacional mexicana en las expresiones artísticas: estudios históricos y contemporáneos. Ciudad de México: UNAM-Plaza y Valdés. pp. 327-338.

Castañeda, Quetzil, (2009) "Aesthetics and Ambivalence of Maya Modernity: The Ethnography of Maya Art", en Jeff Karl Kowalski (editor), Crafting Maya Identity: Contemporary Wood Sculptures from the Puuc Region of Yucatán, Mexico. Estados Unidos: Northern Illinois University Press, DeKalb. pp. 133-151.

Chambers, Erve, (2010) Native Tours: The Anthropology of Travel and Tourism. Long Grove: Waveland Press.

Comaroff, John L. y Jean Comaroff, (2009) Ethnicity, INC. Chicago: University of Chicago Press.

Deleuze, Gilles y Feliz Guattari, (1986) Kafka: Toward a Minor Literature. Minneapolis: University of Minnesota Press.

De Mello, Carolina Luva y Caroline Ciliane Ceretta, (2015) "El souvenir artesanal y la promoción de la imagen del lugar turístico", en Estudios $y$ perspectivas en turismo. Volumen 24, número 2, pp. 188-204. 
Eicher, Joanne B., (1995) Dress and Ethnicity. Oxford: Berg.

Escalona Victoria, José Luis, (2016) "Etnomercancía y sobrefetichización.

Ensayo de mirada estereográfica", en Relaciones. Estudios de Historia y

Sociedad. volumen XXXVII, número 148, pp. 258-288.

Estévez González, Fernando, (2013) "No hay turista sin maleta ni maleta sin souvenir. Performatividad y micropolítica en la experiencia turística", en Museo de Historia y Antropología de Tenerife. Consultado el 8 de febrero de 2019 en: < https://www.museosdetenerife.org/museos-detenerife/evento/3082>

Fernández Repetto, Francisco Javier y Genny Negroe Sierra, (2008) "Entretenimiento, concurso y tradición. Convocatorias y celebraciones de los días de muertos en Mérida”, ponencia presentada en el XII Congreso Latinoamericano de Religión y Etnicidad, Bogotá, Colombia, 7-11 de julio de 2008.

Fernández Repetto, Francisco Javier y Genny Negroe Sierra, (2010) "Catolicismo popular en Yucatán: fiestas patronales y santuarios", en Francisco Fernández Repetto (editor) Estampas etnográficas de Yucatán. Mérida, México: Universidad Autónoma de Yucatán. pp. 77-103.

Figueroa Gómez, Carlos Alejandro, (2014) La mercantilización de la identidad étnica maya: el caso de los artesanos de Chichén Itzá. Tesis para obtener el grado de licenciado en antropología social, Facultad de Ciencias Antropológicas, Universidad Autónoma de Yucatán, Mérida, 2014.

García Canclini, Néstor, (2007) Culturas populares en el capitalismo. Ciudad de México: Grijalbo.

Garza Navejas, Verónica Soledad, (2005) Identidad laboral y artesanias: el caso de las bordadoras de Kimbilá, Yucatán. Tesis para obtener el grado de maestra en ciencias antropológicas, opción antropología social, Facultad de Ciencias Antropológicas, Universidad Autónoma de Yucatán, 2005.

Gobierno del Estado de Yucatán, http://www.yucatan.gob.mx/?p=artesanias [fecha de consulta: 7 de mayo de 2018].

Greenfield, Patricia Marks, (s/f) Tejedoras: generaciones reunidas. Evolución de la creatividad entre los mayas de Chiapas. Singapur: Sna Jtz'ibajom, Cultura de los Indios Mayas, AC, Centro de Investigaciones y Estudios 
Superiores en Antropología Social, Ediciones Fray Bartolomé de las Casas, AC y Ediciones de la Universidad Católica de Chile.

Güémez Pineda, Miguel, (2011) Diccionario del español yucateco. Ciudad de México: Universidad Autónoma de Yucatán y Plaza y Valdés Editores. Hall, Stuart, (1996) “Introduction: Who needs 'Identity”, en: Stuart Hall y Paul du Gay (editores), Questions of Cultural Identity. Londres: Sage. pp. 1-17.

Hendrickson, Carol, (1995) Weaving Identities: Construction of Dress and Self in a Highland Guatemalan Town. Austin: University of Texas Press.

Hendrickson, Carol, (1997) "Imágenes del maya en Guatemala. El papel del traje indígena en las construcciones del indígena y del ladino", en Mesoamérica. Volumen 18, número 33, pp. 15-40.

Hernández Fajardo, Luis, (1944) "Historia de las artes menores", en Carlos A. Echánove Trujillo (director), Enciclopedia yucatanense. Ciudad de México: Gobierno de Yucatán, tomo IV, pp. 823-899.

Hernández-Díaz, Jorge y Gloria Zafra, (2005) Artesanas y artesanos: creación, innovación y tradición en la producción de artesanias. Ciudad de México: Plaza y Valdés.

Larrain, Jorge, (2004) Identidad y modernidad en América Latina. Ciudad de México: Océano.

Llanes Salazar, Rodrigo Alejandro, (2016) "Las reivindicaciones del Pueblo Maya: Etnicidad y poder en Yucatán”, Tesis para obtener el grado de doctor en Ciencias Antropológicas, Universidad Autónoma Metropolitana, Unidad Iztapalapa.

Littlefiled, Alice, (1976) "La industria de las hamacas en Yucatán, México." en Estudio de antropología económica, Instituto Nacional Indigenista, Ciudad de México.

MacCannell, Dean, (1999)[1976] The Tourist: A New Theory of the Leisure Class. Los Angeles y Londres: University of California Press, Berkeley. Mariné-Roig, Estela, (2011) "Innovation and identity in Barcelona's tourist image as represented by souvenirs", en Catalan Journal of Communication and Cultural Studies. Volumen 3, número 2, pp. 175-193.

Martí, Josep, (2012) "La presentación social del cuerpo en el contexto de la globalización y la multiculturalidad. Introducción al dossier”, en 
Revista de Dialectología y Tradiciones Populares. Volumen 47, número 1, pp. 7-18.

Martínez Peñaloza, Porfirio, (1982) Arte popular de México: la creatividad artística del pueblo mexicano a través de los tiempos. Ciudad de México: Panorama.

Medina, Várguez, Alma Teresa, (2016) Artesanias, identidades y turismo en Mérida. Tesis para obtener la licenciatura en Antropología Social, Universidad Autónoma de Yucatán, Mérida.

Millet Cámara, Luis y Ella F. Quintal, (1994) “Traje regional e identidad”, en INJ. Semilla de Maiz. Volumen 8, pp. 25-34.

Novelo, Victoria, (1976) Artesanias y capitalismo en México. Ciudad de México Secretaría de Educación Pública-Instituto Nacional de Antropología e Historia-Centro de Investigaciones Superiores, Instituto Nacional de Antropología e Historia.

Novelo, Victoria, (1981) "Para el estudio de las artesanías mexicanas", en América Indígena. Volumen 2, número 41, pp. 195-210.

Novelo, Victoria, (1993) Las artesanias en México. Tuxtla Gutiérrez: Gobierno del Estado de Chiapas/Instituto Chiapaneco de Cultura.

Otzoy, Irma, (1992) "Identidad y trajes mayas", en Mesoamérica. Volumen 13, número 23, pp. 95-112.

Pérez Montfort, Ricardo, (1994) Estampas de nacionalismo popular mexicano: ensayos sobre cultura popular y nacionalismo. Ciudad de México: Consejo Nacional para la Cultura y las Artes-Centro de Investigación y Estudios Superiores en Antropología Social.

Pérez Montfort, Ricardo, (2007) Expresiones populares y estereotipos culturales en México. Siglos XIX y XX. Diez ensayos. Ciudad de México: Publicaciones de la Casa Chata.

Pérez Montfort, Ricardo, Andrés Villa, Victoria Novelo y Jorge Urzúa, (2009) Mexicanerías: construyendo el México típico. Ciudad de México: CIESAS-Gorila audiovisual $27 \mathrm{~min}$ de antropo-visiones.

Quintal Avilés, Ella F. y otros, (2003) "Solares, rumbos y pueblos: organización social de los mayas peninsulares”, en Saúl Millán y Julieta Valle (coordinadores), La comunidad sin limites. Estructura social y organización comunitaria en las regiones indígenas de México. 
Ciudad de México: Instituto Nacional de Antropología e Historia. Volumen 1, pp. 291-382

Ramos Maza, Teresa, (2004) "Artesanas y artesanías: indígenas y mestizas de Chiapas construyendo espacios de cambio", en LiminaR. Revista de Estudios Sociales y humanísticos. Volumen 2, número 1, pp. 50-71.

Rassmusen, Christian H., Luz Elena Arroyo y Silvia Terán, (2010) Las artesanias en Yucatán. Tradición e innovación. Mérida: Consejo Nacional para la Cultura y las Artes-Instituto de Cultura de YucatánCasa de las artesanías del estado de Yucatán.

Redacción AN, (2018) "No guayaberas y cero contacto físico, determina INE para tercer debate" en Aristegui Noticias. [en línea]. México, disponible en: https://aristeguinoticias.com/0806/mexico/no-guayaberas-ycero-contacto-fisico-determina-ine-para-tercer-debate/. [Consultado el 14 de junio de 2018].

Redfield, Robert, (1945) Yucatán, una cultura de transición. Ciudad de México: Fondo de Cultura Económica.

Redfield, Robert y Alfonso Villa Rojas, (1962) [1934], Chan Kom: A Maya Village. Chicago y Londres: The University of Chicago Press.

Rejón Patrón, Lourdes, (2003) "Tastes, Colors, and Techniques in Embroidered Mayan Female Costumes", en Eli Bartra (editor), Crafting Gender: Women and Folk Art in Latin America and the Caribbean. Durham y Londres: Duke University Press. Kindle Edition.

Rivera Cruz, María Leticia, Pilar Alberti Manzanares, Verónica Vázquez García y Martha Maribel Mendoza Ontiveros, (2008) "La artesanía como producción cultural susceptible de ser atractivo turístico en Santa Catarina del Monte, Texcoco" en Convergencia. Revista de Ciencias Sociales. Número 46, pp. 225-247.

Rotman, Mónica, (2011) "Producciones artesanales, construcción identitaria y dinámica de poder en poblaciones mapuche de Neuquén (Argentina)", en Revista de Antropología Social. Volumen 20, pp. 347-371.

Rubio Herrera, Amada, (2017) "La costura como "verdadero trabajo" masculino en Tekit, Yucatán”, en Península. Volumen XII, número 1, pp. 77-94. 
Ruiz Ávila, Dalia, (2012) "Hipiles yucatecos, flores multicolores. Estética e identidad sociocultural”, en Revista Península. Volumen VII, número 1, pp. 103-122.

Saltzman, Andrea, (2007) El cuerpo diseñado. Sobre la forma en el proyecto de la vestimenta. Buenos Aires: Paidós.

Tun Tun, Heider Ismael, (2013) Artículos suntuarios: maestros artesanos en la industria de muebles Chilovey y talladores de mármol y ónix en Tacali México. Monografía para obtener el grado de licenciado en antropología social, Facultad de Ciencias Antropológicas, Universidad Autónoma de Yucatán, Mérida.

Urzaiz Lares, Enrique, (2011) Rolling cities. Mérida, México: Ediciones de la Universidad Autónoma de Yucatán.

Valenciano-Mané, Alba, (2012) "Vestido, identidad y folklore. La invención de un vestido nacional", en Revista de Dialectología y Tradiciones Populares. Volumen 47, número 1, pp. 267-296.

Vargas-Cetina, Gabriela, (2017) Beautiful Politics of Music: Trova in Yucatán, Mexico. Tuscaloosa: The University of Alabama Press.

Villanueva Villanueva, Nancy, (1983) Artesanias y economía campesina en Halachó, Yucatán. Tesis para obtener el grado de licenciada en Ciencias Antropológicas en la especialidad de Antropología Social, Escuela de Ciencias Antropológicas, Universidad Autónoma de Yucatán, Mérida.

Villanueva Villanueva, Nancy, (1996) Crisis agraria y producción de artesanias. Mérida: Universidad Autónoma de Yucatán.

Walcott, Susan M., (2019) Weaving Identity: Textiles, Global Modernization and Harris Tweed. Oregon: Gluasad Press.

Yanes, Kenneth, (2014), Guatemalan Spanish as Act of Identity: An Analysis of Language and Minor Literature within Modern Maya Literary Production. Tesis para obtener el grado de Maestría en Artes, Facultad de Artes Liberales de la Universidad de la Ciudad de Nueva York, Nueva York. 